\title{
Exploring the responsiveness of public and private hospitals in Lagos, Nigeria
}

\author{
Tomilola Adesanya, ${ }^{3}$ Olayinka Gbolahan, ${ }^{1}$ Obadah Ghannam, ${ }^{1}$ Marisa Miraldo, ${ }^{2}$ \\ Bhavesh Patel, ${ }^{1}$ Rishi Verma, ${ }^{3}$ Heather Wong ${ }^{1}$ \\ ${ }^{1}$ Imperial College School of Medicine, Sir Alexander Fleming Building, South Kensington Campus, \\ London; ${ }^{2}$ Healthcare Management Group, Imperial College Business School, London; ${ }^{3}$ Brighton \& \\ Sussex Medical School, Brighton, UK
}

\begin{abstract}
Significance for public health
This article focuses on measurement of responsiveness in private and public hospitals in Nigerian hospitals and comparing the performance of the two types of providers within this health system performance measure. Measuring performance is crucial for the design of policy interventions that improve service delivery and health outcomes of a population. The impact and relevance for public health is significant.
\end{abstract}

\section{Abstract}

According to the World Health Report 2000, health system responsiveness is proposed as one of the three key objectives of any health system. This multi-domain concept describes how well a health system responds to the expectations of their users concerning the non-health enhancing aspects of care.

In this study we aim to compare the levels of responsiveness experienced by users of private and publicly managed hospitals in Nigeria, and through these insights, to propose recommendations on how to improve performance on this measure.

This quantitative, cross-sectional study uses a questionnaire that is adapted from two responsiveness surveys designed by the World Health Organization (WHO). Researchers collected responses from 520 respondents from four hospitals in Lagos, Nigeria. Analysis of the data using statistical techniques found that significant differences exist between the performance of public and private hospitals on certain domains of responsiveness, with privately operated hospitals performing better where differences exist. Users of private hospitals also reported a higher level of overall satisfaction. Private hospitals were found to perform particularly better on the domains of dignity, waiting times, and travel times. These findings have implications for the management of public hospitals in focusing their efforts on improving their performance in low scoring domains. Performance in these hospitals can be improved by emphasis on staff training and demand management.

\section{Introduction}

In the annual World Health Report published in $2000,{ }^{1}$ the WHO proposed that all health systems should aim to provide a service that improves the health of the population they serve, improves responsiveness and provides financial protection against the cost of ill health.

Responsiveness is the ability of a health system to respond to their users' expectations of the non-health enhancing aspects of their care. The WHO aimed to define responsiveness as a set of domains that are applicable to all health systems, such that performance could be compared between nations. The final set of domains proposed by WHO in 2000 are: autonomy; choice; clarity of communication; confidentiality; dignity; prompt attention; quality of basic amenities; access to social support.

For patients, health system responsiveness is an important consideration as it is the goal that they can most readily comprehend. Due to a lack of expert medical knowledge, patients do not typically understand their prognosis, the reasoning behind medical decisions and the level of health outcomes that should be expected of a particular health system. As such, patients often cannot measure and do not fully consider the quality of health outcomes when making judgements on a health system's performance. However, they can easily relate to the dimensions of responsiveness, which they experience throughout all aspects of treatment.

Since introducing the concept of responsiveness, the WHO conducted the Multi Country Survey Study in 2000-2001 and the World Health Survey in 2002-2004 across a number of countries, such as Bangladesh, China, Ghana and Sweden. These studies used questionnaires to compare the performance of health systems with respect to the three health system performance goals and constituted the seminal pieces of work focussing on responsiveness. Since then, there has been related research that explores responsiveness both on a national as well as an organisational level. However, this has mainly focused in developed countries, with relatively little work studying health system responsiveness in developing nations such as Nigeria. ${ }^{2}$

Available literature suggests that a number of factors may determine how a given population rates the responsiveness of the healthcare they receive. These factors include, the country in which the healthcare is delivered, ${ }^{3}$ the structure of the health system, the type of treatment which is being received, socio-demographic characteristics of the population and the way in which healthcare is financed and delivered. ${ }^{4-6}$ This has implications when generalising findings about responsiveness that have been gained from studies conducted in other health systems to the Nigerian context.

There is also a gap in the literature with respect to how responsiveness varies between public and private hospitals, particularly in the context of developing nations such as Nigeria. As such, further research is warranted to explore the performance of Nigerian healthcare providers in terms of responsiveness.

Our contribution aims to fill the above gaps by building on two existing strands in the literature. The first strand of literature consists of the notable contributions of Bleich et al., ${ }^{7}$ and Pletzer and colleagues $^{8}$ in exploring the responsiveness of public and private health care providers. 
Bleich and colleagues ${ }^{7}$ compared the satisfaction rates of public and private healthcare users in 21 European Union countries using data from the World Health Survey. The study identified lower satisfaction rates amongst private healthcare users compared to public healthcare users, which is the opposite of Peltzer's findings. ${ }^{8}$ However, this study is limited to developed countries, specifically within the European Union and as the performance of public hospitals compared to private hospitals may be context specific, further investigation of the institutional performance in Nigeria is required.

Pelzer and colleagues analysed data collected from the World Health Survey on South Africa of 2352 public and private healthcare users. ${ }^{8}$ They found the degree of responsiveness to be significantly lower in public hospitals than in private hospitals. Our research departs from their analysis in two significant ways. Firstly, we study responsiveness in the Nigerian context. Secondly, we combine the satisfaction elicited in their study with i) a measure of patients actual experiences within each domain and ii) a measure of the importance of each domain from the patient's perspective.

The second strand of literature relating to our research consists of studies developed in the Nigerian context that are relevant to the responsiveness domains. Any current understanding on Nigeria's performance in terms of responsiveness is fragmented, with various studies using different measurements of these domains. Work by Ofovwe and 0 fili ${ }^{9}$ and Iliyasu and colleagues ${ }^{10}$ studied the levels of satisfaction with different aspects of care at University of Benin Teaching Hospital and at Aminu Kano Teaching Hospital, respectively. While their questionnaires incorporated some domains of responsiveness, not all domains were included.

Their studies do, however, show significant variation in health service performance throughout Nigeria. As such, more research is warranted to investigate how responsiveness is delivered in previously unstudied areas of Nigeria, such as the state of Lagos. Therefore, conducting our research in this state adds to the existing research in other areas of Nigeria.

In summary, our study will aim to address above literature gaps by studying how public and private health services perform in Nigeria under the responsiveness framework as proposed by the WHO. This information is important for policy makers in Nigeria, trying to bridge the gap in performance between public and private healthcare.

\section{The data}

\section{The questionnaire}

A patient's experience and their satisfaction with that experience are often quite different. Many factors external to the health system influence satisfaction beyond patient experience with the system. ${ }^{7}$ One such factor is patient expectations ${ }^{11}$ and according to Maister, ${ }^{12}$ the relationship between satisfaction and expectation can be explained by the following equation:

\section{Satisfaction $=$ Perception - Expectation}

As a result, our questionnaire will measure both users' experience of responsiveness (perception) and how satisfied users are with these experiences. It shall also measure how important the aspects of responsiveness are to users. The relationship between these three measures will then be assessed. This is a novel approach as no previous research into responsiveness has measured and compared experience, satisfaction and importance for each of the responsiveness domains.
Such an approach is important for policy makers since it guides allocation of resources. For example, policy makers should focus on domains that are considered most important and perform poorly on experience or satisfaction measures.

We collected our data in early 2011 using a cross-sectional, quantitative survey of 520 health care users in Lagos, Nigeria. The WHO devised the Multi-Country Survey Study and World Health Survey, two questionnaires containing sections specifically designed to measure responsiveness. They were designed to be suitable for collecting data in any country and have been validated by the WHO. We built upon these by using the relevant questions to form our questionnaire. The wording and order of the questions were kept as close to the original as possible in order to maintain a high level of validity. However, some minor modifications were made in order to make it more applicable to the Nigerian context, for example, the addition of a question to elicit the respondent's tribe.

The questionnaire consisted of four sections. The first elicited participants' socio-demographic characteristics. The second asked them to report their experiences with each of the domains. The third section asked participants to rate their satisfaction with the domains and the final section asked them how important each domain was to them.

The second, third and fourth part of the questionnaire had different questions in order to capture the respondent's satisfaction, experience and importance of the following domains of responsiveness: the ability of a patient to be involved in decision-making regarding their care including permission taking prior to tests and being given information about other types of treatment (autonomy); the power to choose the health institution or healthcare provider (choice); the clarity of communication by healthcare providers in conveying adequate information clearly including sufficient time for the patient to ask questions (communication); the level of privacy of patients medical information within and outside medical consultations including the level of confidentiality kept over personal records (confidentiality); whether patients receive care in a respectful and caring manner from medical and non-medical staff (dignity); access to care including waiting times for consultations and travel times to hospitals (prompt attention); and how welcoming and pleasant the physical infrastructure of the health facility is to the patient including the cleanliness of the institution and how much space, seating and fresh air was available (quality of basic amenities).* (Questionnaire, Appendix 1.)

Whilst primary care exists, those needing healthcare often go directly to hospitals, which have general outpatient departments specifically to provide ambulatory care. ${ }^{4}$ Therefore, the distinction between primary and secondary care is often unclear. For the purposes of this study, data was collected from outpatients departments of hospitals only. As such, the final domain of responsiveness (access to social support networks) was not included in our questionnaire as this only applies to inpatients and hence was not relevant to our study sample.

Data was collected in the general outpatient departments of four hospitals in Lagos consisting of two public hospitals (General Hospital Lagos Marina and Lagos University Teaching Hospital) and two private hospitals (St Nicholas Hospital and Reddington Hospital). They all offer a similar range of services, which limits a case-mix bias.

Since most patients attend on a drop-in basis, the research team approached everyone visiting outpatients, including patients and their accompanying friends and relatives, which provided an opportunity sample. Particular care was taken to approach all potential participants to ensure there was no bias in selecting certain people to participate in the study.

*Note that since the scope of our analysis focus on outpatient treatment we do not cover the domain access to social support as this domain applied to inpatient care. 
All participants were asked to sign a consent form prior to taking part. Permission from the relevant ethics committees and hospital managers was granted for us to conduct our fieldwork at each site.

To complement our analysis, the General Manager of Reddington Hospital and Chief Medical Director of General Hospital Lagos were interviewed to gain a further understanding of the challenges in delivering a responsive health service from a management perspective.

\section{The sample}

A total number of 520 questionnaires were completed. The nonresponse rate in both of the private hospitals was less than $10 \%$ (25/270) and less than 5\% (10/250) in the public hospitals.

The final sample consisted of 237 (45.5\%) males and 283 (54.5\%) were female (Table 1, Appendix 2). Compared to the Nigerian population the sample had proportionately more females than males with the national proportions at $51 \%$ males and $49 \%$ females. ${ }^{13}$

The sample median age was 36.2 years (Table 2, Appendix 2) compared to 19.2 years, the median age of the Nigerian population. Nigeria is composed of over 250 ethnic groups with $29 \%$ of the population being Hausa, $21 \%$ being Yoruba and $18 \%$ being Igbo.13 From the sample 10 (2.3\%) were of the Hausa tribe, 241 (56.4\%) were of the Yoruba tribe, $111(26.0 \%)$ were of the Igbo tribe, $65(15.2 \%)$ were of other tribes (Table 1, Appendix 2). The sample was conducted in Lagos, the south of Nigeria, which is predominantly a Yoruba state; this explains the large proportion of Yoruba people compared to Hausa people. The Nigerian population is 50\% Muslim and $40 \%$ Christian. $10 \%$ of the population has indigenous beliefs. ${ }^{13}$ The sample consisted predominantly of Christians (75.9\%), with $22.7 \%$ of people being Muslim and $1.4 \%$ being of other faiths (Table 1, Appendix 2). Once again this is more reflective of the south of Nigeria, with the majority of Muslims being based in the north.

Public users generally had lower education levels with the largest number of people in the second category (secondary school completed). Private users had higher educational levels with the largest number of people in the third category (university completed). Income group II (N50,000 - N99,999) has the highest number of public users whereas income group VI (N150,000 - N199,999) has the highest number of private users.

\section{Analysis}

We analysed the data using SPSS. ${ }^{14}$ For the satisfaction, experience and importance sections, reliability tests were conducted as many questions were asked for each domain. These reliability tests elicited how these questions could be grouped back together into the 7 different domains. Cronbach's Alpha was used to measure the internal consistency between variables. Internal consistency was assumed for all results with Cronbach's Alpha based on standardised items $>0.600$.

The two-sample Kolmogorov-Smirnov test was used to assess normality of the data in SPSS. On the basis of the normality of our data, appropriate parametric (independent and paired samples t-tests) and non parametric (Mann Whitney U Test, Spearman's Rank correlation Test and Wilcoxon Signed Rank Sum Test) were chosen. For all tests, a p value of 0.05 was chosen for statistical significance. Tables 1-4 in Appendices present the main results.

\section{Results}

Reliability test showed that all questions to be grouped into domains were reliable except in case of waiting times and travel times, which were originally part of the prompt attention domain. These were therefore kept as prompt attention A (waiting times) and prompt attention B (travel times) respectively throughout the analysis.

There was no significant difference in ratings of health on the day between public and private users $(\mathrm{P}=0.961)$ (Table 4 , Figure 1 in Appendix 2). Private users generally used private transport (68\%) whilst public users travelled using public transport (64\%) (Table 3, Appendix 2). There were no differences in private and public users' ratings of the healthcare provider skill (Table 5, Appendix 2). Private users rated the way healthcare in Nigeria involves them in deciding what services it provides and where it provides them as lower that public users rated it $(\mathrm{P}=0.025)$ (Table 4, Figure 1 in Appendix 2). Results also suggest that the private users were less satisfied with the way the healthcare system is run than public users $(\mathrm{P}=0.000)$ (Table 4, Figure 1 in Appendix 2).

\section{Discussion}

Tables 1 and 2 highlight the main results that are most relevant to the discussion.

Table 2 shows the ranking of the domains in order of importance for the patients. The three most important domains were clear communication, quality of basic amenities and confidentiality.

With respect to experience, private hospital users generally had better experiences than public hospital users and were also more satisfied (Table 1). For experience, the domains that contributed to this difference were dignity, waiting times (prompt attention A) and travel times (prompt attention B). However, the domains leading to greater satisfaction for private users were dignity, choice and quality of basic amenities (see results in Table 1).

Regarding prompt attention, private patients experienced shorter waiting times (prompt attention A), compared to public users as they waited, on average, 49 minutes compared to the 127 minute wait by public users (Table 1) . As explained by Dr. B., the Chief Medical Director of General Hospital (interwieved by B. Patel and H. Wong on March $\left.16^{\text {th }}, 2011\right)$, this is due to public hospitals exceeding capacity. Results for waiting times in public hospitals are similar to those found in previous studies in public sector outpatient clinics. ${ }^{15,16}$ Despite this, public and private hospital users were not significantly different in their satisfaction with the waiting time, nor were there significant differences in the importance placed on waiting times by the two populations (Table 1).

The difference in waiting times between the public and private hospitals can be explained by the demand management techniques. In public hospitals, patients were only given appointments for a particular day and not time. The queues were then managed on a first-come-firstserved basis; therefore, patients were not seen immediately. Other the other hand private healthcare providers staggered demand using specific time slots and thus patients waited for less time.

Along with shorter waiting times, private patients experienced shorter travel times to hospitals compared to public users. Journey time for private patients was on average $42 \mathrm{~min}$, while users of public healthcare travelled, on average, for $67 \mathrm{~min}(\mathrm{P}=0.001)$ (Table 1$)$. This may be explained by the fact that most private patients travelled to hospital via their own vehicles whereas public patients' main mode of transport was public (Table 3, Appendix 2). Once again there was no significant difference in satisfaction between the two populations, possibly 
because expectations of travel times were lower for public transport users.

For the dignity domain, data analysis suggests that private users had a significantly higher experience of dignity when compared to public users (Table 1). They were shown more respect by healthcare providers and hospital office staff, and had physical examinations conducted in a way that respected the subjects' privacy more than public hospital users.

Following on from this, it is no surprise that private users generally rated their satisfaction with dignity as significantly higher than public users (Table 1). In the private health sector in Lagos, there is much competition due to the abundance of hospitals. ${ }^{17}$ For these profit-motivated hospitals, the attitudes of employees, including both healthcare providers and office staff, are key to high quality service delivery and patient retention. Private hospitals therefore put more effort into recruiting, training and retaining good quality staff. Public hospitals, which are non-profit organisations, have less of an incentive to focus on patient retention and dignity.

Quality of basic amenities was ranked as one of the three most important domains (Table 2). Private users were more satisfied and had a better experience than public users (Table 1). The manager of General Hospital cited the lack of space as the biggest challenge in delivering a responsive health system. He discussed that whilst the number of patients and staff have increased, no new rooms have been added. This was putting additional strain on the infrastructure and resources at the hospital.

When carrying out fieldwork it was realised that in the Nigerian con- text, this domain should include additional questions on amenities that are specific to the Nigerian context such as electricity. Electricity is a major concern for a hospital such as General Hospital, which depends on the provision of electricity through generators rather than through the national grid. The Chief Medical Director mentioned whilst they now have a greater ability to generate electricity, the price for diesel has gone up. Thus they needed to prioritise how they use their limited energy supply.

Private hospital users were more satisfied with their choice of healthcare provider than public users (Table 1); this would appear to be due to capacity limitations in public hospitals. The Chief Medical Director of General Hospital stated that although many patients wanted to see specific doctors, this was not plausible most of the time. Conversely the manager at Reddington Hospital (Mr. C., interwieved by B. Patel and H. Wong on March 18th, 2011) mentioned that patients' requests for a particular doctor were usually upheld.

The difference in experience of this domain was not significant between public and private hospital users (Table 1). Two of the four questions to elicit the experience of choice were not used due to a poor response rate (see Appendix 1). As such the experience results are not robust.

Choice of healthcare provider had the lowest score for importance out of the eight domains (Table 7, Appendix 4). As with autonomy, this may be due to the paternalistic culture of healthcare in Nigeria; patients may be more trusting of doctors in general and may not mind which healthcare provider they see.

Clarity of communication was found to be the most important

Table 1. Rank across domains.

\begin{tabular}{|c|c|c|c|}
\hline $\begin{array}{l}\text { Domain } \\
\text { OVERALL }\end{array}$ & $\begin{array}{l}\text { Experience } \\
\text { PRIVATE } \\
\text { (see Appendix } 2 \text { Table VI) }\end{array}$ & $\begin{array}{l}\text { Satisfaction } \\
\text { PRIVATE } \\
\text { (see Appendix } 2 \text { Table VI) }\end{array}$ & $\begin{array}{l}\text { Importance } \\
\text { PRIVATE } \\
\text { (see Appendix 2 Table VI) }\end{array}$ \\
\hline Prompt attention - waiting times & $\begin{array}{l}\text { PRIVATE } \\
(\mathrm{P}=0.000)\end{array}$ & $\begin{array}{l}\text { Insignificant } \\
(\mathrm{P}=0.678)\end{array}$ & $\begin{array}{l}\text { Insignificant } \\
(\mathrm{P}=0.226)\end{array}$ \\
\hline Prompt attention - travel times & $\begin{array}{l}\text { PRIVATE , } \\
(\mathrm{P}=0.001)\end{array}$ & $\begin{array}{l}\text { Insignificant } \\
(\mathrm{P}=0.078)\end{array}$ & $\begin{array}{l}\text { Insignificant } \\
(\mathrm{P}=0.060)\end{array}$ \\
\hline Dignity & $\begin{array}{l}\text { PRIVATE } \\
(\mathrm{P}=0.000)\end{array}$ & $\begin{array}{l}\text { PRIVATE } \\
(\mathrm{P}=0.018)\end{array}$ & $\begin{array}{l}\text { Insignificant } \\
(\mathrm{P}=0.718)\end{array}$ \\
\hline Choice of health care provider & $\begin{array}{l}\text { Insignificant } \\
(\mathrm{P}=0.112)\end{array}$ & $\begin{array}{l}\text { PRIVATE } \\
(\mathrm{P}=0.000)\end{array}$ & $\begin{array}{l}\text { PRIVATE } \\
(\mathrm{P}=0.000)\end{array}$ \\
\hline Quality of basic amenities & $\begin{array}{l}\text { PRIVATE } \\
(\mathrm{P}=0.000)\end{array}$ & $\begin{array}{l}\text { PRIVATE } \\
(\mathrm{P}=0.000)\end{array}$ & $\begin{array}{l}\text { Insignificant } \\
(\mathrm{P}=0.066)\end{array}$ \\
\hline Clear communication & $\begin{array}{l}\text { Insignificant } \\
(\mathrm{P}=0.504)\end{array}$ & $\begin{array}{c}\text { Insignificant } \\
(\mathrm{P}=0.225)\end{array}$ & $\begin{array}{l}\text { Insignificant } \\
(\mathrm{P}=0.343)\end{array}$ \\
\hline Confidentiality & $\begin{array}{l}\text { Insignificant } \\
(\mathrm{P}=0.558)\end{array}$ & $\begin{array}{l}\text { Insignificant } \\
(\mathrm{P}=0.652)\end{array}$ & $\begin{array}{l}\text { Insignificant } \\
(\mathrm{P}=0.591)\end{array}$ \\
\hline Autonomy & $\begin{array}{l}\text { Insignificant } \\
(\mathrm{P}=0.158)\end{array}$ & $\begin{array}{l}\text { Insignificant } \\
(\mathrm{P}=0.350)\end{array}$ & $\begin{array}{l}\text { Insignificant } \\
(\mathrm{P}=0.089)\end{array}$ \\
\hline
\end{tabular}

Table 2. Ranking of mean ratings (from highest to lowest) for domain importance of public, private and all users.

\begin{tabular}{lllll}
\hline Public means & & Private means & Means for all users \\
Clear communication & 4.83 & Clear communication & 4.78 & Clear communication \\
Confidentiality & 4.68 & Quality of basic amenities & 4.56 & Quality of basic amenities \\
\hline Quality of basic amenities & 4.63 & Confidentiality & 4.56 & Confidentiality \\
Dignity & 4.57 & Travel times (prompt attention B) & 4.46 & Dignity \\
\hline Travel times (prompt attention B) & 4.54 & Dignity & 4.42 & Travel times (prompt attention B) \\
Autonomy & 4.51 & Choice of healthcare provider & 4.33 & Autonomy \\
\hline Waiting times (prompt attention A) & 4.47 & Autonomy & 4.30 & Waiting times (prompt attention A) \\
Choice of healthcare provider & 4.42 & Waiting times (prompt attention A) & 4.21 & Choice of healthcare provider \\
\hline
\end{tabular}


domain for both private and public users thus it is important for all hospitals to perform well in this domain (Table 2). However, there were no significant differences in satisfaction, experiences or importance between the two private and public providers in this domain (Table 1).

Public and private providers also performed equally on autonomy and confidentiality domains.

\section{Conclusions}

We collected primary data in public and private hospitals within Lagos, Nigeria using a quantitative data collection instrument. This built upon questionnaires developed by the World Health Organization to measure responsiveness. We also complemented the discussion of our quantitative findings using insights from interviews with key stakeholders.

Using statistical analyses, we found that private hospitals performed better in terms of experiences and satisfaction of responsiveness. However, there was no difference in the importance of responsiveness to users of both types of hospital. We also found that overall, experience of responsiveness was higher than patients satisfaction of responsiveness but that these experiences are not great enough for how important responsiveness is to them.

The data shows that public hospitals are less responsive with regards to the domains of prompt attention and dignity.

We propose that through improved demand management and a focus on enhancing the role of primary care in Lagos, public hospitals can reduce their waiting times. Furthermore through investing in the relationships between management, their staff and their patients, public hospitals can perform better on the domain of dignity.

Correspondence: Dr. Marisa Miraldo, Healthcare Management Group, Imperial College Business School, Tanaka Building, London, SW7 2AZ, UK. Tel.+44.20.75895111. E-mail: m.miraldo@imperial.ac.uk

Key words: health system performance, responsiveness, public and private providers.

Contributions: all authors contributed equally to this work.

Conflict of interest: the authors declare no conflicts of interest.

Received for publication: 30 November 2011.

Accepted for publication: 20 December 2011.

CCopyright T. Adesanya et al., 2011

Licensee PAGEPress, Italy

Journal of Public Health Research 2012; 1:e2

doi:10.4081/jphr.2012.e2

This work is licensed under a Creative Commons Attribution NonCommercial 3.0 License (CC BY-NC 3.0).

\section{References}

1. Musgrove P, Creese A, Preker A, et al. World Health Report 2000. Report number 6, World Health Organization, Geneva, Switzerland.

2. Valentine N, de Silva A, Kawabata K, et al. Responsiveness: concepts domains and operationalization. In: C. Murray C and D. Evans (eds.) Health systems performance assessment: debates methods and empiricism. 2003, World Health Organization, Geneva, Switzerland, pp. 573-593.

3. Valentine N, Darby C, Bonsel GJ. Which aspects of non-clinical quality of care are most important? Results from WHO's general population surveys of "health systems responsiveness" in 41 countries. Soc Sci Med 2008;66:1939-50.

4. Ajayi I0, Olumide EA, Oyediran 0. Patient satisfaction with the services provided at a general outpatients' clinic, Ibadan, Oyo State, Nigeria. Afr J Med Med Sci 2005;34:133-40.

5. Bramesfeld A, Wedegartner F, Elgeti H, Bisson S. How does mental healthcare perform in respect to service users' expectations? Evaluating inpatient and outpatient care in Germany with the WHO responsiveness concept. BMC Health Serv Res 2007;7:99.

6. Fawole A, Okunlola M, Adekunle A. Clients' perceptions of the quality of antenatal care. J NatL Med Assoc 2008;100:1052-8.

7. Bleich S, Özaltin E, Murray C. How does satisfaction with the health-care system relate to patient experience? Bull World Health Organ 2009;87:271-8.

8. Peltzer K. Patient experiences and health system responsiveness in South Africa. BMC Health Serv Res 2009;9:117.

9. Ofovwe $\mathrm{C}$, Ofili A. Indices of patient satisfaction in an African population. Public Health 2005;119:582-6.

10. Iliyasu Z, Abubakar I, Abubakar S, et al. Patients' satisfaction with services obtained from Aminu Kano Teaching Hospital, Kano, Northern Nigeria. Niger J Clin Pract 2010;13:371-8.

11. Murray C, Kawabata K, Valentine N. People's experience versus people's expectations. Health Affairs 2001;20:21-4.

12. Maister D. The psychology of waiting lines. In: J. Czepiel, M. Solomon and C. Surprenant (eds.) The Service encounter: managing employee/customer interaction in service businesses. 1985 Lexington Books, Lexington, MA, USA.

13. Central Intelligence Agency US. The World Factbook: Nigeria. Accessed on: 15 November 2011. Available from: https:/www.cia. gov/library/publications/the-world-factbook/geos/ni.html

14. IBM. SPSS Statistics 19 [CD-ROM]. IBM, 2010.

15. Oladapo T, Iyaniwura C, Sule-Odu A. Quality of antenatal services at the primary care level in southwest Nigeria. Afr J Reprod Health 2008;12:71-92.

16. Orenuga 00, Sofola 00, Uti 00. Patient satisfaction: a survey of dental outpatients at the Lagos University Teaching Hospital, Nigeria. Nig Q J Hosp Med 2009;19:47-52.

17. World Health Organization. Health System Policies and Service Delivery. Accessed on: 9 December 2010. Available from: http://www.who.int/countries/nga/areas/health_systems/en/index.h tml. 